\title{
Canal Transportation, Centering Ability, and Dentin Removal after Instrumentation: A Micro-CT Evaluation
}

\author{
Mônica S de Albuquerque ${ }^{1}$, Armiliana S Nascimento ${ }^{2}$, Ivan O Gialain ${ }^{3}$, Eliane A de Lima ${ }^{4}$, Jeysiellen AF Nery ${ }^{5}$, \\ Poliana R de Souza Araujo ${ }^{6}$, Rebeca F de Menezes ${ }^{7}$, Augusto S Kato ${ }^{8}$, Rodivan Braz ${ }^{9}$
}

\begin{abstract}
Aim: The aim of this study is to evaluate and compare root canal transportation, centering ability, and amount of dentin removed after root instrumentation with different rotary and reciprocating systems, using micro-computed tomography (micro-CT).

Materials and methods: Forty curved mesial canals of lower molars were selected and divided into four experimental groups ( $n=10)$ according to the system used: protaper next (PTN), wave one gold (WOG), prodesign logic (LOG), and vortex blue (VTX). The roots were scanned before and after instrumentation using micro-CT, with a $16 \mu \mathrm{m}$ isotropic resolution.

Results: Data were statistically analyzed using the Bioestat and the significance level was set at 0.05 . For canal transportation, no significant differences were verified between the groups at $6 \mathrm{~mm}$ or $9 \mathrm{~mm}$ from the apex. At the apical third, LOG had a smaller mesial deviation when compared with PTN. A significant difference was found at the apical and coronal thirds, though with LOG having the best centering ability at the apical third and the worst one at the coronal third. All systems caused a greater wear at the coronal third ( $9 \mathrm{~mm})$, decreasing at the apical one $(3 \mathrm{~mm})$, with statistically significant differences. LOG removed less dentin from the apical third $(3 \mathrm{~mm})$ than did the other instruments.

Conclusion: The systems evaluated presented different results for canal transportation, centering ability, and dentin removal at each third.

Clinical significance: The systems were evaluated together to evaluate neither the marked dental deviations nor the long-term signifiers of the databases and they were evaluated within the limits of normality. Therefore, they can be used without risks of embrittlement of the dental roots. Keywords: Centering ability, Root canal treatment, Rotary instrumentation, Transportation.

The Journal of Contemporary Dental Practice (2019): 10.5005/jp-journals-10024-2601
\end{abstract}

\section{INTRODUCTION}

The development of rotary instruments has led to the eventual improvement of root canal mechanical preparation ${ }^{1}$ and an increasing number of rotary instruments have been launched on the market, differing from each other in the design of the cutting blades and in the configurations of file tip and handle. Nowadays, endodontic files are made of superplastic nickel-titanium (Ni-Ti) alloys, whose thermomechanical processing includes the martensitic phase, which remains stable under clinical conditions. ${ }^{2}$ These alloys increase the flexibility and resistance of instruments to cyclic fatigue, with consequent conical root canal preparations and reduction of failure, when compared to conventional Ni-Ti alloys. ${ }^{3}$ The literature reports that $\mathrm{Ni}-\mathrm{Ti}$ files, besides allowing for conical root canal preparation, lead to a more centered shape with minimal deviations from the root canal central axis. ${ }^{4}$

However, when the instrument is subjected to stress within the canal, reciprocations interrupted and undue stresses are generated in the dentin during instrumentation. ${ }^{5,6}$ Especially, in curved canals, cleaning and instrumentation pose a challenge when such systems are used, because it is difficult to maintain the long axis centered, increasing the risks of deviations, excessive wear of canal walls, punching, formation of steps, and fracture. ${ }^{7}$ In these cases, the process of cutting the dental tissue is controversial, since both friction and stress may increase, ${ }^{8}$ leading to canal transportation and resulting in poorly cleaned and/or over instrumented root canals with loss of fracture resistance. ${ }^{9}$

Some techniques have been proposed to evaluate root canal shaping after instrumentation, with a special focus on micro- $\mathrm{CT}^{10,11}$ because of its nondestructive nature and its ability to analyze highresolution samples. ${ }^{12}$ Thus, the aim of this study is to use micro-CT
1,2,4-7,9 Department of Dentistry, University of Pernambuco-UPE, Tabatinga, Camaragibe, State of Pernambuco, Brazil

${ }^{3}$ Department of Stomatology, School of Dentistry, University of São Paulo, São Paulo, Brazil

${ }^{8}$ Department of Endodontics, São Leopoldo Mandic Dental Research Center, São Paulo, Brazil

Corresponding Author: Mônica S de Albuquerque, Department of Dentistry, University of Pernambuco-UPE, Tabatinga, Camaragibe, State of Pernambuco, Brazil, Phone: +55 (81)995432705, e-mail: santos.albuquerque@hotmail.com

How to cite this article: de Albuquerque MS, Nascimento AS, et al. Canal Transportation, Centering Ability, and Dentin Removal after Instrumentation: A Micro-CT Evaluation. J Contemp Dent Pract 2019;20(7):806-811.

Source of support: Nil

Conflict of interest: None

to evaluate and compare apical transportation, centering ability, and amount of dentin removal after root instrumentation with different rotary and reciprocating systems. The null hypothesis was that there would be no difference between the systems regarding the analyzed variables.

\section{Materials and Methods}

\section{Selection of Teeth and Initial Micro-CT Scanning}

The study protocol was approved by the Research Ethics Committee of the University of Pernambuco (UPE), Pernambuco, Brazil (CAAE 55563516.9.0000.5207). A total of 40 curved mesial canals of lower

() The Author(s). 20190pen Access This article is distributed under the terms of the Creative Commons Attribution 4.0 International License (https://creativecommons. org/licenses/by-nc/4.0/), which permits unrestricted use, distribution, and non-commercial reproduction in any medium, provided you give appropriate credit to the original author(s) and the source, provide a link to the Creative Commons license, and indicate if changes were made. The Creative Commons Public Domain Dedication waiver (http://creativecommons.org/publicdomain/zero/1.0/) applies to the data made available in this article, unless otherwise stated. 
molars, with independent canals and foramina and with similar length, diameter, and degree of curvature $\left(20^{\circ}-40^{\circ}\right)$ were selected. Based on a pilot study with 16 canals carried out with $\mathrm{G}^{*}$ Power software (v. 3.1.9.2, Kiel, Germany), the total sample was composed of 40 canals. The selection was made by radiographic examination (mesiodistal and buccolingual measurements) and inspection under 40x stereomicroscopic magnification (Nikon, Tokyo, Japan). Teeth with defective roots, cracks and/or pre-identified fractures, pulp nodules, internal resorption, previous endodontic treatment, and open apices were excluded. The crowns were sectioned approximately $2 \mathrm{~mm}$ above the cementoenamel junction to standardize root length and to facilitate the positioning of the samples during micro-CT analysis. The roots were pre-scanned at a 16- $\mu \mathrm{m}$ isotropic resolution using a micro-CT device (XTH225ST; Nikon, Tokyo, Japan) operating at $90 \mathrm{kV}$ and $278 \mu \mathrm{A}$, with a $360^{\circ}$ vertical rotation axis and a $0.5 \mathrm{~mm}$ aluminum filter. The obtained images were reconstructed using the NRecon software v.1.6.9 (Bruker-micro CT) with artifact correction. The samples evaluated in the preoperative period served as a control for the respective postoperative evaluations.

\section{Division of Groups and Preparation of Canals}

All canals were explored with a manual K-file \#10 (Dentsply/ Maillefer, Switzerland), operating at the true canal length, and the working length was set at $0.5 \mathrm{~mm}$ from the apical foramen. The roots were then divided into four groups according to the rotary system used. All systems were used with the same motor (X-Smart Plus; Dentsply, Maillefer, Ballaigues, Switzerland) and a new file was used for each sample. The preparation of the cervical third was performed using the instruments of each system for the intended purpose:

- Protaper next (PTN) - the files were rotated at $300 \mathrm{rpm}$ using a 2.0- $\mathrm{N} \mathrm{cm}$ torque in the following sequence: SX (35.03) inserted up to two-thirds of the working length and $X 1$ (17.04) and X2 (25.06) at all working lengths.

- Wave one gold (WOG) - the wave one gold primary \#25.07 sequence was used in a single session at the working length.

- Prodesign logic (LOG) - the files were used at 350-800 rpm with a torque of 1.0-4.0 N cm in the following order: \#25.01 and \#25.06 at the working length with three back-and-forth movements.

- Vortex blue (VTX) —operating system with rotation of $500 \mathrm{rpm}$ and torque of $1.3 \mathrm{~N} \mathrm{~cm}$ in the following sequence: $30 / 04$ followed by $25 / 04$ at the working length.

During instrumentation, the canal was irrigated with $2.5 \%$ of the sodium hypochlorite solution $(2 \mathrm{~mL})$. At the end, the canal was flooded with $17 \%$ of the EDTA (F\&A Laboratório Farmacêutico Ltda, São Paulo, Brazil), and mechanical agitation was performed with the Easy Clean System (Easy-Equipamentos Odontológicos, Jardinópolis, Belo Horizonte, MG, Brazil), with subsequent irrigation with $\mathrm{NaOCl}(2.5 \%)$, aspiration, and drying with absorbent paper points (Dentsply/Maillefer, Switzerland). The same irrigation protocol was applied to all groups.

\section{Postoperative Micro-CT Analysis}

After canal preparation, the roots were re-scanned using micro-CT and the same previously described parameters. The data were saved and the images were exported in the TIFF format into an image analysis software (ImageJ/FIJI software, public domain, National Institute of Health, Bethesda, MD, USA) (Fig. 1A), and later saved and exported in the Wavefront Object format using a threshold of 150 . Subsequently, the three-dimensional meshes of the same tooth, both pre- and post-instrumentation, were imported into the MeshLab software. Using the point base gluing commanded, the three-dimensional models were overlaid on the same spatial coordinates (Fig. 1B) and each model was saved into stereolithography (SL) format, being later imported into the Rhinoceros 3D software (Robert Mc Neel \& Associates, Seattle, WA) where the root canal mesh was separated from each tooth, respecting the distance of 1-10 $\mathrm{mm}$ from the apex. The total volume of the root canal was obtained from this new mesh (Fig. 1C).

Three cross-sections were made in each mesh at $3 \mathrm{~mm}$ (apical third), $6 \mathrm{~mm}$ (middle third), and $9 \mathrm{~mm}$ (cervical third) from the apex, where the canal area and the smallest distances between the canal lumen and the external root wall were calculated, both for the mesial and distal regions and for the canal area (Figs 2A and B). Transportation, canal centering ability, and dentin wear (Fig. 2C) were calculated from these values, as described by Gambill et al. ${ }^{13}$

\section{Statistical Analyses}

The results were presented as mean \pm standard deviation (SD) for each variable. The values for dentin removal, centering ability, and canal transportation were inserted into a Microsoft Excel (Microsoft, Redmond, WA, USA) spreadsheet. The Shapiro-Wilk normality test was performed for all variables and groups. After that, either one-way ANOVA with Tukey's post hoc test or Kruskal-Wallis with Dunn's post hoc test was performed to compare the different file systems, whereas repeated-measures ANOVA with Tukey's post hoc or the Friedman test was conducted to compare the values obtained for the canal thirds. All tests were carried out with the Biostat software (v. 5.3, Instituto Mamirauá, Tefé, Brazil), with a $95 \%$ significance level $(p<0.05)$.

\section{Results}

No significant differences in canal transportation were verified between the groups at $6 \mathrm{~mm}$ or $9 \mathrm{~mm}$ from the apex. At the apical third, LOG had a smaller mesial deviation when compared with PTN. When the difference among the thirds was accounted for each system, there were significant differences in the WOG group, with deviations of the mesial and distal root canals at the apical and middle thirds, respectively (Table 1 ).

As far as centering ability is concerned, a significant difference was found at the apical and coronal thirds. LOG showed the best centering ability at the apical third and the worst one at the coronal third. When comparing values obtained after instrumentation with VTX and LOG, VTX showed better centering ability at the middle than at the apical third, and LOG showed lower centering ability at the coronal third when compared with the apical and middle thirds (Table 2).

The initial internal volume of the root canal was similar between the groups and increased after instrumentation with each system, but without statistical difference among the file systems (Fig. 3).

Table 3 shows the mean and the standard deviation for tooth wear for each third (apical, middle, and cervical). Results show that all systems caused a greater wear at the coronal third $(9 \mathrm{~mm})$, decreasing at the apical one $(3 \mathrm{~mm})$, with statistically significant differences. There were differences at the cervical and apical thirds when the groups were compared. PTN and WOG caused greater wear at the coronal third, while LOG showed less dentin removal from the apical third. 

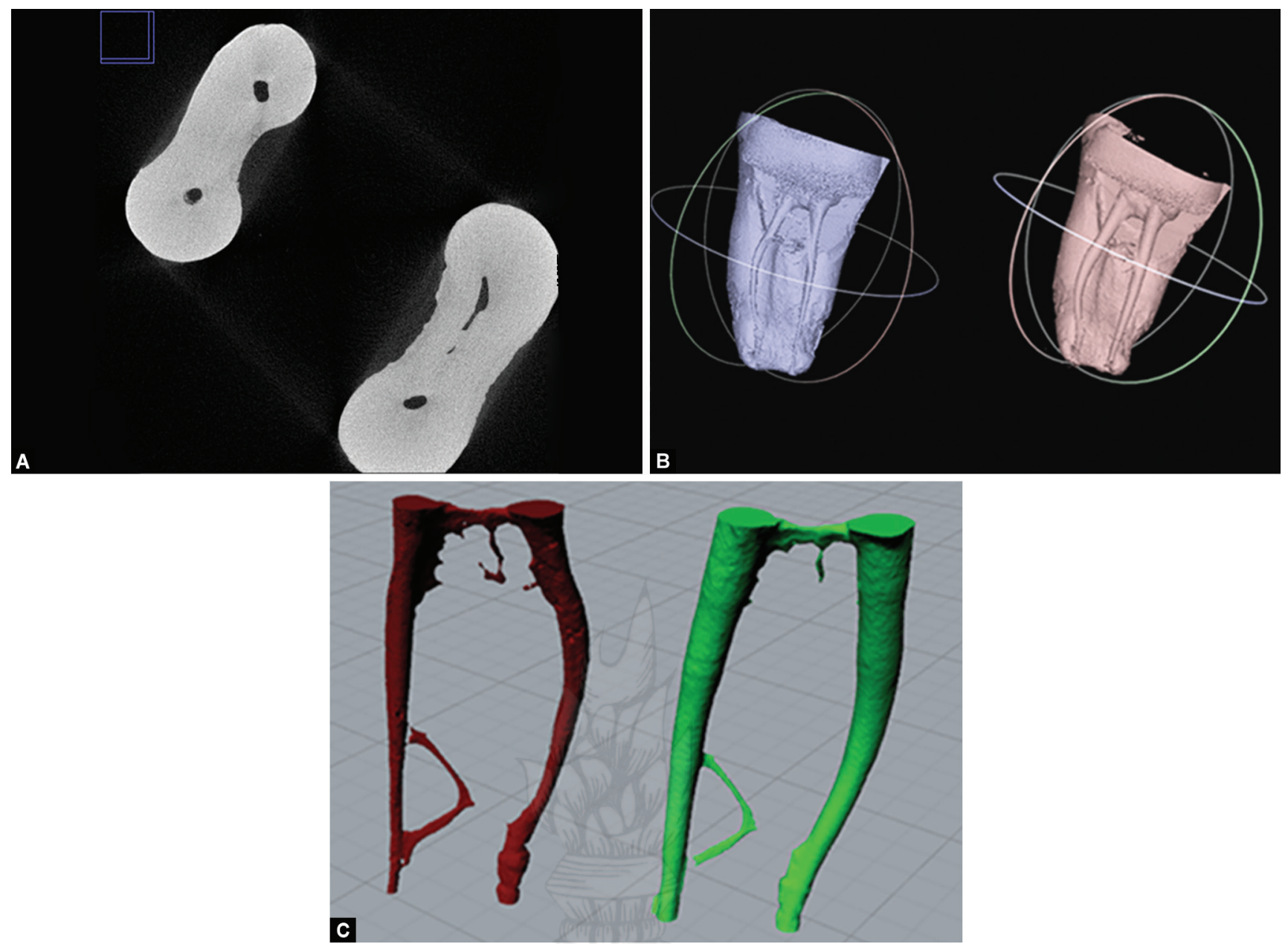

Figs 1 A to C: Representative image of the microtomographic analysis: (A) Image before (right) and after (left) root canal preparation in TIFF format, using ImageJ/FIJI software (National Institute of Health, Bethesda, MD, USA); (B) Images in wave front object (.obj) format; (C) Images in sterolithography (.stl) format, analyzed by Rhinoceros 3D software (Robert Mc Neel \& Associates, Seattle, WA)

\section{Discussion}

This study evaluated and compared canal transportation, centering ability, and the wear of dentin tissue by four rotary and reciprocating systems in curved canals of lower molars. The images were obtained by micro-CT, which is noninvasive and the gold standard for assessing canal geometry and the efficiency of cast models. ${ }^{14,15}$ This imaging technique all owed comparing the anatomical structure of the root canal before and after instrumentation.

The null hypothesis that there would be no difference between the systems and the analyzed variables was partially rejected. In the evaluation of canal transportation, no statistically significant differences were found between the files at $6 \mathrm{~mm}$ and $9 \mathrm{~mm}$, despite some differences in deviation, corroborating the studies of Carvalho et al. ${ }^{16}$ and Saber et al., ${ }^{17}$ who also did not find differences among the evaluated systems. In this study, PTN and WOG presented greater deviation from the original canal path, at the middle and apical thirds, compared to VTX and LOG. Changes in the internal canal anatomy may result in iatrogenic defects and/or root fractures ${ }^{9,18}$ and, more frequently, in the presence of debris and microorganisms in uninstrumented areas, which increases postoperative failure. ${ }^{19}$ The images of each third revealed statistically significant differences between LOG and PTN regarding canal transportation at the apical third.
Canal transportation was evaluated considering the changes on the central axis of the root canal after instrumentation. Results show that all of the systems used caused minimum deviations, but they had active tip design, geometry, diameter, and different types of alloys. PTN and VTX are composed of M-wire alloys. The former has a new design called offset, in which the central mass of the instrument is displaced outside the central axis. ${ }^{20-22}$ The latter shows improvements in its resistance to cyclic fatigue and flexibility. These characteristics may explain the satisfactory results obtained by VTX. LOG also presented better micro-CT results, attributable to its characteristics and composition. It is manufactured using controlled memory wire, whose different phase transformation behavior could be ascribed to its special thermomechanical processing. WOG has the same kinematics as wave one; however, a parallelogram-shaped cross-section with two cutting edges was used, increasing its flexibility, and a new surface heat treatment was carried out. ${ }^{23}$

Centering ability was analyzed according to the methodology proposed by Gambill et al., ${ }^{13}$ who defined it as the ability of the endodontic instrument to remain on the central axis of the root canal. At the apical and middle thirds, LOG showed better centering ability. At the coronal third, WOG yielded better results, differing statistically from LOG. On the one hand, Saleh et al. ${ }^{24}$ showed that the high conicity of reciprocating systems is one of the causes for 

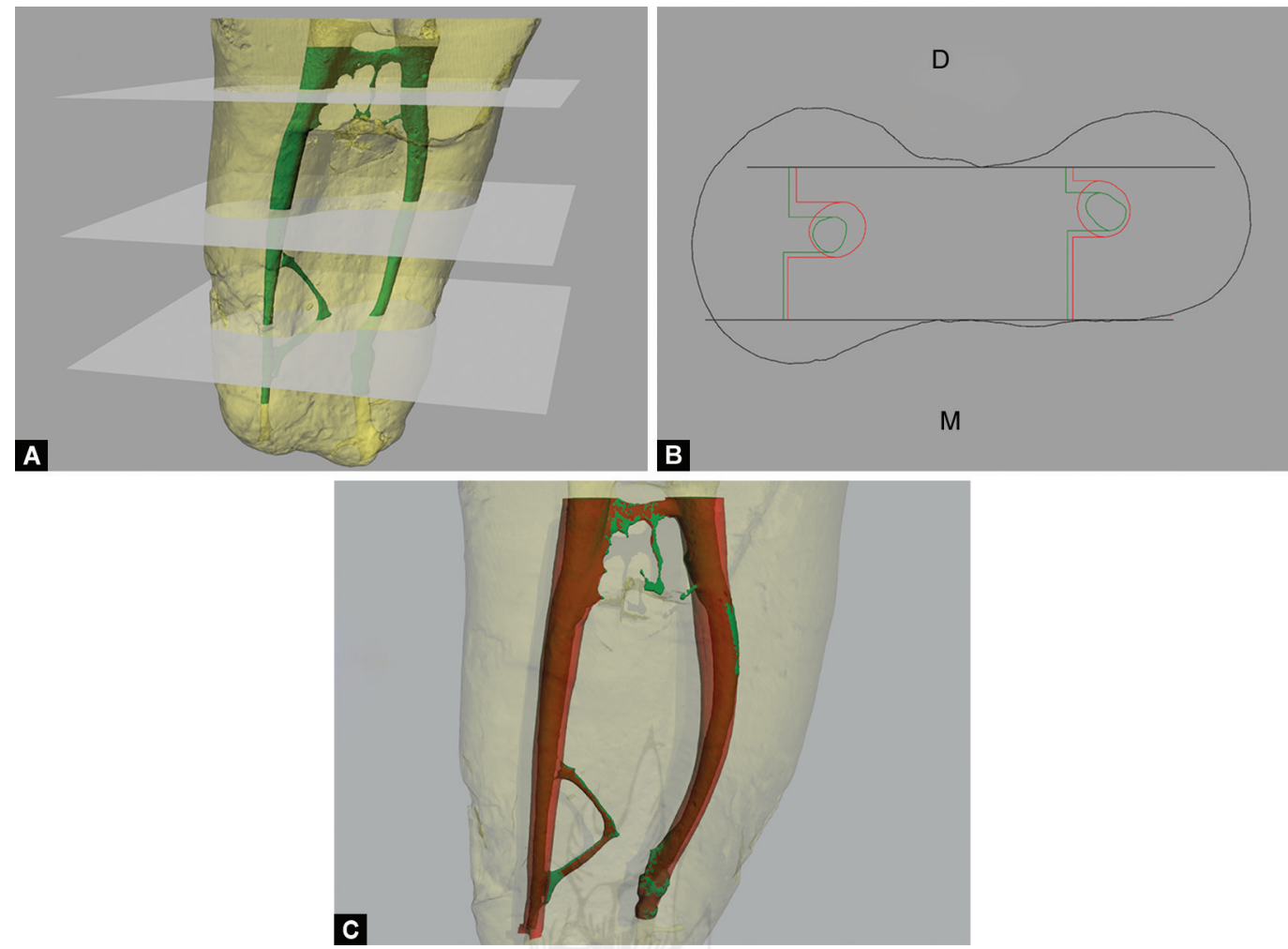

Figs $2 \mathrm{~A}$ and C: (A) Cross-sections $-3 \mathrm{~mm}, 6 \mathrm{~mm}$, and $9 \mathrm{~mm}$ from the apex; (B) Representative cross-sectional diagram of mesial and distal distances from the canal lumen to the external root surface, pre- and post-instrumentation; (C) Initial (green) and final (red) volume

Table 1: Canal transportation for each root canal third. Positive values show mesial transportation; negative values show distal transportation. Values in $\mathrm{mm}$

\begin{tabular}{lllll}
\hline & Apical third & Middle third & Coronal third & \\
\cline { 2 - 3 } Instrument system & Mean $\pm S D$ & Mean $\pm S D$ & Mean $\pm S D$ & $p$ value \\
\hline WOG & $0.049 \pm 0.077^{(\mathrm{A}, \mathrm{ab})}$ & $-0.074 \pm 0.088^{(\mathrm{B}, \mathrm{a})}$ & $0.016 \pm 0.074^{(\mathrm{AB}, \mathrm{a})}$ & $p^{(1)}<0.05$ \\
VTX & $0.019 \pm 0.047^{(\mathrm{A}, \mathrm{ab})}$ & $-0.012 \pm 0.109^{(\mathrm{A}, \mathrm{a})}$ & $0.054 \pm 0.100^{(\mathrm{A}, \mathrm{a})}$ & $p^{(1)}=0.27$ \\
PTN & $0.078 \pm 0.065^{(\mathrm{A}, \mathrm{a})}$ & $-0.029 \pm 0.078^{(\mathrm{A}, \mathrm{a})}$ & $-0.005 \pm 0.156^{(\mathrm{A}, \mathrm{a})}$ & $p^{(1)}=0.06$ \\
LOG & $0.015 \pm 0.025^{(\mathrm{A}, \mathrm{b})}$ & $0.008 \pm 0.040^{(\mathrm{A}, \mathrm{a})}$ & $0.031 \pm 0.219^{(\mathrm{A}, \mathrm{a})}$ & $p^{(1)}=0.67$ \\
$p$ value & $p^{(2)}<0.05$ & $p^{(2)}=0.146$ & $p^{(2)}=0.719$ & \\
\hline
\end{tabular}

(1) By the Friedman test. (2) By the Kruskal-Wallis test with Dunn post hoc. Note: if all capital letters in parentheses are different, a significant difference between the corresponding distances is verified. If all lowercase letters are distinct, a significant difference between the corresponding groups (file types) is verified

Table 2: Centralization ratio of root canal preparation for each root canal third

\begin{tabular}{lllll}
\hline & Apical third & Middle third & Coronal third & \\
\cline { 2 - 4 } Instrument system & Mean $\pm S D$ & Mean $\pm S D$ & Mean $\pm S D$ & $p$ value \\
\hline WOG & $0.431 \pm 0.270^{(\mathrm{A}, \mathrm{ab})}$ & $0.542 \pm 0.309^{(\mathrm{A}, \mathrm{a})}$ & $0.600 \pm 0.268^{(\mathrm{A}, \mathrm{a})}$ & $p^{(1)}=0.57$ \\
VTX & $0.669 \pm 0.169^{(\mathrm{A}, \mathrm{b})}$ & $0.393 \pm 0.277^{(\mathrm{B}, \mathrm{a})}$ & $0.505 \pm 0.296^{(\mathrm{AB}, \mathrm{ab})}$ & $p^{(1)}<0.05$ \\
PTN & $0.288 \pm 0.183^{(\mathrm{A}, \mathrm{a})}$ & $0.493 \pm 0.261^{(\mathrm{A}, \mathrm{a})}$ & $0.460 \pm 0.250^{(\mathrm{A}, \mathrm{ab})}$ & $p^{(1)}=0.12$ \\
LOG & $0.692 \pm 0.170^{(\mathrm{A}, \mathrm{c})}$ & $0.675 \pm 0.239^{(\mathrm{A}, \mathrm{a})}$ & $0.264 \pm 0.172^{(\mathrm{B}, \mathrm{b})}$ & $p^{(1)}<0.05$ \\
$p$ value & $p^{(2)}<0.05$ & $p^{(2)}=0.157$ & $p^{(2)}<0.05$ & \\
\hline
\end{tabular}

(1) By the Friedman test. (2) By the one-way ANOVA test with Tukey post hoc. Note: if all capital letters in parentheses are different, a significant difference between the corresponding distances is verified. If all lowercase letters are distinct, a significant difference between the corresponding groups (file types) is verified

the lower maintenance of a centered canal, which is at odds with the findings of this study.

On the other hand, some authors ${ }^{16,25,26}$ reported that $\mathrm{Ni}-\mathrm{Ti}$ instruments activated by continuous rotation and/or reciprocation have a greater ability to create more centered preparations, thus, reducing canal transportation. It has also been demonstrated that the use of reciprocating files provides a more conservative preparation than continuous rotation systems because a single 
Table 3: Area of dentin tissue removed for each root canal third. Values in $\mathrm{mm}^{2}$

\begin{tabular}{lllll}
\hline & Apical third & Middle third & Coronal third & \\
\cline { 2 - 3 } Instrument system & Mean $\pm S D$ & Mean $\pm S D$ & Mean $\pm S D$ & $p$ value \\
\hline WOG & $0.095 \pm 0.043^{(\mathrm{A}, \mathrm{a})}$ & $0.187 \pm 0.077^{(\mathrm{AB}, \mathrm{a})}$ & $0.303 \pm 0.064^{(\mathrm{B}, \mathrm{a})}$ & $p^{(1)}<0.05$ \\
VTX & $0.082 \pm 0.026^{(\mathrm{A}, \mathrm{ab})}$ & $0.111 \pm 0.035^{(\mathrm{B}, \mathrm{a})}$ & $0.183 \pm 0.060^{(\mathrm{C}, \mathrm{b})}$ & $p^{(1)}<0.05$ \\
PTN & $0.064 \pm 0.041^{(\mathrm{A}, \mathrm{ab})}$ & $0.139 \pm 0.072^{(\mathrm{B}, \mathrm{a})}$ & $0.324 \pm 0.098^{(\mathrm{C}, \mathrm{a})}$ & $p^{(1)}<0.05$ \\
LOG & $0.046 \pm 0.029^{(\mathrm{A}, \mathrm{b})}$ & $0.116 \pm 0.047^{(\mathrm{B}, \mathrm{a})}$ & $0.233 \pm 0.098^{(\mathrm{C}, \mathrm{ab})}$ & $p^{(1)}<0.05$ \\
$p$ value & $p^{(2)}<0.05$ & $p^{(2)}=0.052$ & $p^{(2)}<0.05$ & \\
\hline
\end{tabular}

(1) By the Friedman test. (2) By the Kruskal-Wallis test with Dunn post hoc. Note: if all capital letters in parentheses are different, a significant difference between the corresponding distances is verified. If all lowercase letters are distinct, a significant difference between the corresponding groups (file types) is verified

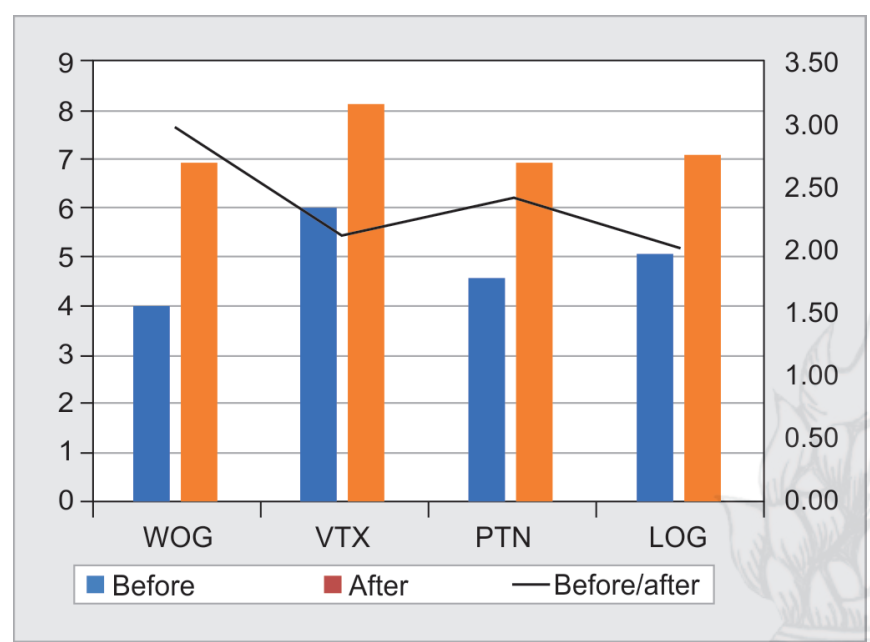

Fig. 3: Mean and difference of the total internal volume of the canal before and after instrumentation

instrument is used to shape the root canal, while the rotary system uses a sequence of files. $6,27,28$

The results obtained in this study indicate an increase in volume and diameter of the root canal after instrumentation $(p>0.05)$, but tissue removal was lower than that which could be considered a potential risk for root fracture. ${ }^{29}$ According to Wilcox et al., ${ }^{30}$ a dentin tissue removal greater than $40 \%$ predisposes the root to fractures, which are more frequent in the mesial roots of lower molars. ${ }^{31}$ Sometimes, the increase in volume does not indicate a higher percentage of instrumented areas; instead, it may negatively affect resistance to dental fracture. ${ }^{7}$ However, recent results, based on large studies of sections obtained from patients, have shown that there are more tooth extractions after endodontic treatment due to restorative rather than endodontic factors. ${ }^{10,32}$

When the wear of dentin tissue was analyzed at each third, the systems behaved differently, with less wear by LOG at the apical third, corroborating the results of studies performed with one shape and TFA systems with a constant taper of 0.06 , which explains why less dentin was removed when the Reciproc was used. ${ }^{24,33}$ At the middle and coronal thirds, VTX removed less dentin, followed by LOG, with statistical differences between the systems and thirds. This is an important finding because although canal preparation should be large enough to control infection, coronal enlargement must be carefully performed to avoid root weakening. ${ }^{34}$ PTN and WOG removed a greater amount of dentin at the coronal and middle thirds, corroborating the results obtained by Shivashankar et al. ${ }^{35}$ with the use of different tapers for PTN files.

\section{Limitations of this Study}

As limitations we have that in addition to being an in vitro study, we did not use experimental prototype simulating hemi-mandible, in this we could approach a little of the clinical conditions, since the roots would be inserted in its alveolus.

\section{Conclusion}

Both rotary and reciprocating systems yielded different results for canal transportation, centering ability, and dentin removal at each third, but the changes were not large enough to weaken any of the teeth.

\section{ACKNOWLedgments}

The authors wish to thank Mr Daniel Amancio Duarte for technical assistance with micro-CT measurements, as well as Professor Antonio Celso Dantas Antoníno, from the Federal University of Pernambuco (Department of Nuclear Energy).

\section{References}

1. Hulsmann M, Peters OA, et al. Mechanical preparation of root canals: shaping goals, techniques and means. Endod Topics 2005;10(1):30-76. DOI: 10.1111/j.1601-1546.2005.00152.x.

2. Plotino G, Grande NM, et al. Blue treatment enhances cyclic fatigue resistance of vortex nickel-titanium rotary files. J Endod 2014;40(9):1451-1453. DOI: 10.1016/j.joen.2014.02.020.

3. Larsen CM, Watanabe I, et al. Cyclic fatigue analysis of a new generation of nickel titanium rotary instruments. J Endod 2009;35(3):401-403. DOI: 10.1016/j.joen.2008.12.010.

4. Vaudt J, Bitter K, et al. Ex vivo study on root canal instrumentation of two rotary nickel-titanium systems in comparison to stainless steel hand instruments. Int Endod J 2009;42(1):22-23. DOI: 10.1111/j.13652591.2008.01489.x.

5. Gambarini G, Testarelli $L$, et al. The influence of three different instrumentation techniques on the incidence of postoperative pain after endodontic treatment. Ann Stomatal (Roma) 2013 Mar 20;4(1):152-155. DOI: 10.11138/ads/2013.4.1.152.

6. Capar ID, Arslan H, et al. Effectiveness of ProTaper Universal retreatment instruments used with rotary or reciprocating adaptive motion in the removal of root canal filling material. Int J Endod 2015;48(1):79-83. DOI: 10.1111/iej.12279.

7. Coelho BS, Amaral RO, et al. Performance of three single instrument systems in the preparation of long oval canals. Braz Dent J 2016;27(2):217-222. DOI: 10.1590/0103-6440201302449.

8. Pasqualini D, Scotti N, et al. Hand-operated and rotary ProTaper instruments: a comparison of working time and number of rotations in simulated root canals. J Endod 2008;34(3):314-317. DOI: 10.1016/ j.joen.2007.12.017.

9. Kumar SR, Gade V. Canal-centering ability. Med Sci 2014;10:246-248. 
10. Peters $\mathrm{OA}$, Arias $\mathrm{A}$, et al. A micro-computed tomographic assessment of root canal preparation with a novel instrument, TRU shape, in mesial roots of mandibular molars. J Endod 2015;41(9):1545-1550. DOI: 10.1016/j.joen.2015.06.007.

11. Zhang $\mathrm{Q}$, Chen $\mathrm{H}$, et al. Root and root canal morphology in maxillary second molar with fused root from a native Chinese population. J Endod 2014;40(6):871-875. DOI: 10.1016/j.joen.2013.10.035.

12. Fan $B, Y e W$, et al. Three-dimensional morphological analysis of C-shaped canals in mandibular first premolars in a Chinese population. Int J Endod 2012;45(11):1035-1041. DOI: 10.1111/j.13652591.2012.02070.x.

13. Gambill JM, Alder M, et al. Comparison of nickel-titanium and stainless steel hand-file instrumentation using computed tomography. J Endod 1996;22(7):369-375. DOI: 10.1016/S0099-2399(96)80221-4.

14. Rhodes JS, Ford TR, et al. Micro computed tomography: a new tool for experimental endodontology. Int Endod J 1999;32(3):165-170. DOI: 10.1046/j.1365-2591.1999.00204.x.

15. Stern $S$, Patel $S$, et al. Changes in centering and shaping ability using three nickel-titanium instrumentation techniques analysed by microcomputed tomography $(\mu C T)$. Int Endod J 2012;45(6):514-523. DOI: 10.1111/j.1365-2591.2011.02004.x.

16. de Carvalho GM, Sponchiado Junior EC, et al. Apical transportation, centering ability, and cleaning effectiveness of reciprocating singlefile system associated with different glide path techniques. J Endod 2015;41(12):2045-2049. DOI: 10.1016/j.joen.2015.09.005.

17. Saber SE, Nagy MM, et al. Comparative evaluation of the shaping ability of Wave One, Reciproc, and One Shape single-file systems in severely curved root canals of extracted teeth. Int Endod J 2015;48(1):109-114. DOI: 10.1111/iej.12289.

18. Moura-Netto C, Palo RM, et al. Micro-CT assessment of two different endodontic preparation systems. Braz Oral Res 2013;27(1):26-30. DOI: 10.1590/S1806-83242013000100005.

19. Wu MK, Fan B, et al. Leakage along apical root fillings in curved root canals. Part I: effects of apical transportation on seal of root fillings. J Endod 2000;26(4):210-216. DOI: 10.1097/00004770-20000400000003.

20. Zhao D, Shen $Y$, et al. Root canal preparation of mandibular molars with 3 nickel-titanium rotary instruments: a micro-computed tomographic study. J Endod 2014;40(11):1860-1864. DOI: 10.1016/ j.joen.2014.06.023.

21. Ruddle CJ, Machtou P, et al. The shaping movement: fifth-generation technology. Dent Today 2013;32(4):94, 96-99.

22. Elnaghy AM, Elsaka SE. Evaluation of root canal transportation, centering ratio, and remaining dentin thickness associated with ProTaper Next instruments with and without glide path. J Endod 2014;40(2):2053-2056. DOI: 10.1016/j.joen.2014.09.001.
23. Cassimiro M, Romeiro K, et al. Albuquerque occurrence of dentina defects after root canal preparation with R-phase, M-Wire and Gold Wire instruments: a micro-CT analysis. BMC Oral Health 2017;17(1):93. DOI: 10.1186/s12903-017-0387-0.

24. Saleh AM, Gilani PV, et al. Shaping ability of 4 different single-file systems in simulated S-shaped canals. J Endod 2015;41(4):548-552. DOI: 10.1016/j.joen.2014.11.019.

25. Pagliosa A, Sousa-Neto MD, et al. Computed tomography evaluation of rotary systems on the root canal transportation and centering ability. Braz Oral Res 2015;29:1-7. DOI: 10.1590/1807-3107BOR-2015. vol29.0039.

26. Gergi R, Osta N, et al. Effects of three nickel titanium instrument systems on root canal geometry assessed by micro-computed tomography. Int Endod J 2015;48(2):162-170. DOI: 10.1111/iej.12296.

27. Hwang $\mathrm{YH}, \mathrm{Bae} \mathrm{KS}$, et al. Shaping ability of the conventional nickel-titanium and reciprocating nickel-titanium file systems: a comparative study using micro-computed tomography. J Endod 2014;40(8):1186-1189. DOI: 10.1016/j.joen.2013.12.032.

28. Higuera O, Plotino G, et al. Cyclic fatigue resistance of 3 different nickel-titanium reciprocating instruments in artificial canals. J Endod 2015;41(6):913-915. DOI: 10.1016/j.joen.2015.01.023.

29. Adorno CG, Yoshioka T, et al. The effect of endodontic procedures on apical crack initiation and propagation ex vivo. Int Endod J 2013;46(8):763-768. DOI: 10.1111/iej.12056.

30. Wilcox LR, Roskelley $C$, et al. The relationship of root canal enlargement to finger-spreader induced vertical root fracture. J Endod 1997;23(8):533-534. DOI: 10.1016/S0099-2399(97)80316-0.

31. Lertchirakarn V, Palamara JE, et al. Patterns of vertical root fracture: factors affecting stress distribution in the root canal. J Endod 2003;29(8):523-528. DOI: 10.1097/00004770-200308000-00008.

32. Borén $\mathrm{DL}$, Jonasson $\mathrm{P}$, et al. Long-term survival of endodontically treated teeth at a public dental specialist clinic. J Endod 2015 Feb;41(2):176-181. DOI: 10.1016/j.joen.2014.10.002.

33. Capar ID, Ertas H, et al. Comparative study of different novel nickeltitanium rotary systems for root canal preparation in severely curved root canals. J Endod 2014 Jun;40(6):852-856. DOI: 10.1016/ j.joen.2013.10.010.

34. Rodrigues $\mathrm{RCV}$, Zandi $\mathrm{H}$, et al. Influence of the apical preparation size and the irrigant type on bacterial reduction in root canal-treated teeth with apical periodontitis. J Endod 2017;43(7):1058-1063. DOI: 10.1016/j.joen.2017.02.004.

35. Shivashankar MB, Niranjan NT, et al. Computed tomography evaluation of canal transportation and volumetric changes in root canal dentin of curved canals using Mtwo, ProTaper and ProTaper Next rotary system - an in vitro study. J Clin Diagn Res 2016;10(11):ZC10-ZC14. DOI: 10.7860/JCDR/2016/20373.8788. 